\title{
The oxanorbornene approach to 3-hydroxy, 3,4- dihydroxy and 3,4,5-trihydroxy derivatives of 2-aminocyclohexanecarboxylic acid
}

\author{
Ishmael B. Masesane ${ }^{* 1,2}$, Andrei S. Batsanov ${ }^{1}$, Judith A. K. Howard ${ }^{1}$, \\ Raju Mondal ${ }^{1}$ and Patrick G. Steel ${ }^{1}$
}

\section{Full Research Paper}

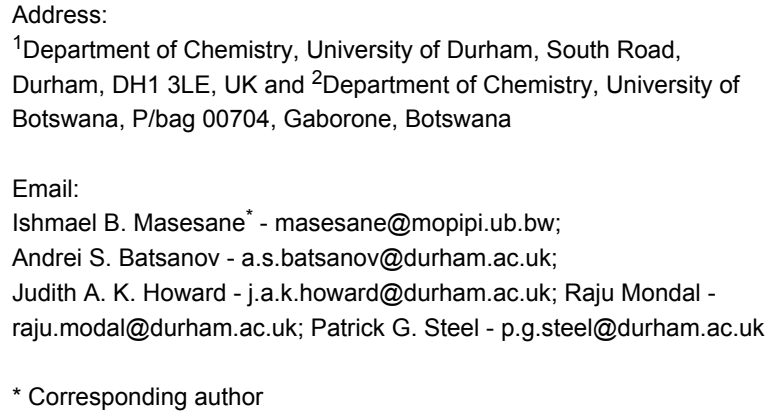

${ }^{1}$ Department of Chemistry, University of Durham, South Road, Durham, DH1 3LE, UK and ${ }^{2}$ Department of Chemistry, University of Botswana, P/bag 00704, Gaborone, Botswana

Email:

Ishmael B. Masesane* - masesane@mopipi.ub.bw;

Andrei S. Batsanov - a.s.batsanov@durham.ac.uk;

Judith A. K. Howard - j.a.k.howard@durham.ac.uk; Raju Mondal -

raju.modal@durham.ac.uk; Patrick G. Steel - p.g.steel@durham.ac.uk

* Corresponding author

\author{
Beilstein Journal of Organic Chemistry 2006, 2, No. 9 \\ doi:10.1186/1860-5397-2-9 \\ Received: 18 April 2006 \\ Accepted: 04 May 2006 \\ Published: 04 May 2006 \\ (C) 2006 Masesane et al; licensee Beilstein-Institut. \\ License and terms: see end of document.
}

\section{Abstract}

The nitro oxanorbornene adduct derived from the Diels-Alder reaction of ethyl (E)-3-nitroacrylate and furan provides a versatile template for the stereoselective synthesis of hydroxylated derivatives of 2-aminocyclohexanecarboxylic acid (ACHC).

\section{Introduction}

In recent years there has been a surge of interest in cyclic $\beta$-amino acids and this has been accompanied by the proliferation of procedures for their synthesis.[1] Much of the interest in these compounds emanate from the ability of oligomers or short polymers of cyclic $\beta$-amino acids to adopt well-defined secondary structures analogous to those of natural peptides. [2-9] Such oligomers therefore have a particular appeal for extending understanding of protein structure and stabilization. However, much of this work has focused on simple cyclic $\beta$-amino acids and analogous studies of substituted derivatives are less well developed. One reason for this is that simple stereocontrolled routes to such derivatives have not been defined. In this respect, we have been exploring the use of oxanorbornene adducts derived from the Diels-Alder reaction of ethyl $(E)$-3-nitroacrylate and furan as versatile intermediates in the synthesis of a range of novel hydroxylated derivatives of 2-aminocyclohexanecarboxylic acid (ACHC). In previous preliminary communications we have described the application of the endo nitro adduct to the synthesis of various polyhydroxylated analogues.[10,11] In this paper, we provide the full details of this work and additionally describe the stereoselective synthesis of further novel hydroxylated derivatives of ACHC using the exo nitro oxanorbornene adduct as the template. The basis of our approach to these poly hydroxylated cyclohexane $\beta$-amino acids was the recognition that the bicyclic oxanorbornene cycloadduct, derived from the Diels-Alder reac- 


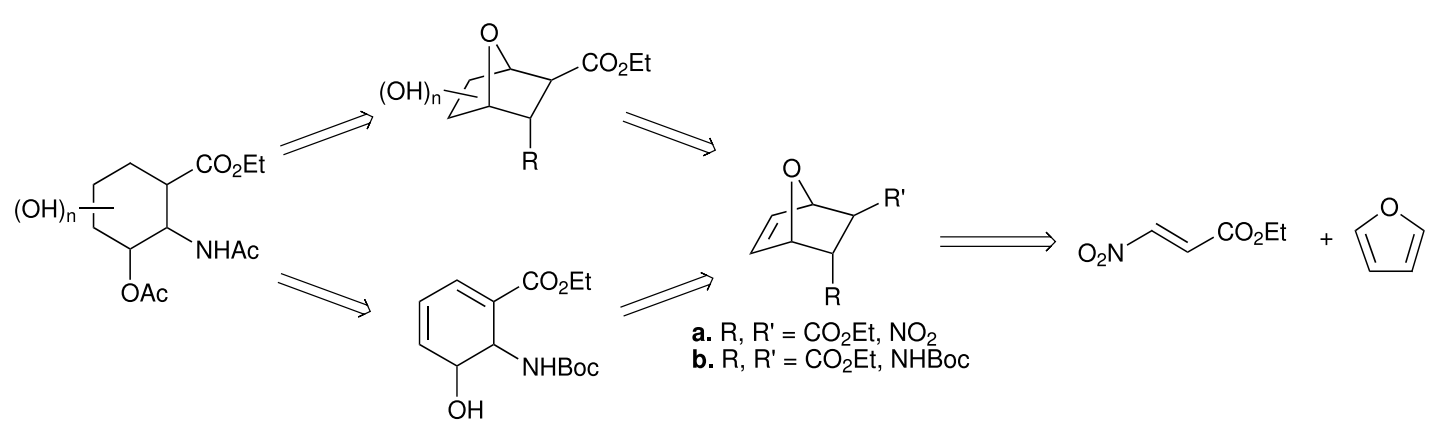

Scheme 1: The furan-nitroacylate approach to poly hydroxylated $\mathrm{ACHC}$ derivatives

tion between furan and ethyl nitroacrylate, represented a versatile template that could be elaborated to the desired targets via a variety of complementary oxidative processes coupled with a base promoted ring fragmentation, Scheme 1.

\section{Results and Discussion Oxanorbornene Synthesis}

Efficient access to ethyl (E)-3-nitroacrylate 1 was achieved through a modification of the McMurry procedure involving the reaction of ethyl acrylate with $\mathrm{N}_{2} \mathrm{O}_{4}$ and $\mathrm{I}_{2}$ followed by careful elimination of HI with Hunig's base in ether.[12] With this sequence of reactions, 1 could be generated in 10-20 g batches, Scheme 1. Whilst this dienophile reacts with considerable regiocontrol (dominated by the nitro group) the stereoselectivity (endo:exo ratio) observed is frequently minimal. [13-15] Subjection of nitroacrylate 1 to cycloaddition reaction with furan in $\mathrm{CHCl}_{3}$ at room temperature gave a 2:1 mixture of cycloadducts favouring the endo nitro isomer $2 \mathbf{a}$, Scheme 2 . Increased endo selectivity could be achieved by carrying out the reaction at $-20^{\circ} \mathrm{C}$ for 5 days, giving a $4: 1$ mixture of the two isomers in $90 \%$ yield. Attempts to further enhance this ratio through the use of a range of Lewis acids or alternative solvents were not successful. Interestingly, Just and co-workers have reported the preference for the exo-nitro adduct when the reaction of methyl 3-nitroacrylate and furan was carried out without a solvent.[16] However, in our hands, this reaction afforded a 3:1 mixture in favour of the endo-nitro adduct.

The two isomeric cycloadducts were easily separated by column chromatography. Whilst initial attempts to reduce the nitro group were complicated by difficulties in the isolation of the resultant amine, an efficient one-pot conversion into the protected aminoesters $\mathbf{2} \mathbf{b}$ and $\mathbf{3 b}$ was achieved by reduction with $\mathrm{Zn} / \mathrm{HCl}$ followed by addition of (Boc) $)_{2} \mathrm{O}$ and a large excess of ${ }^{i} \operatorname{Pr}_{2}$ NEt. At this stage, confirmation of the correct assignment of the relative stereochemistry for each isomer was realised by an X-ray crystallographic structure determination of the endo carbamate $\mathbf{2 b}$ (see Supporting Information File 1 for details).

\section{3-Hydroxy-2-aminocyclohexanecarboxylic acids}

With the oxanorbornene template available in quantities we then explored the based promoted fragmentation needed to generate the 3-hydroxy-2-aminocyclohexanecarboxylate core. Related base promoted transformations have been described in

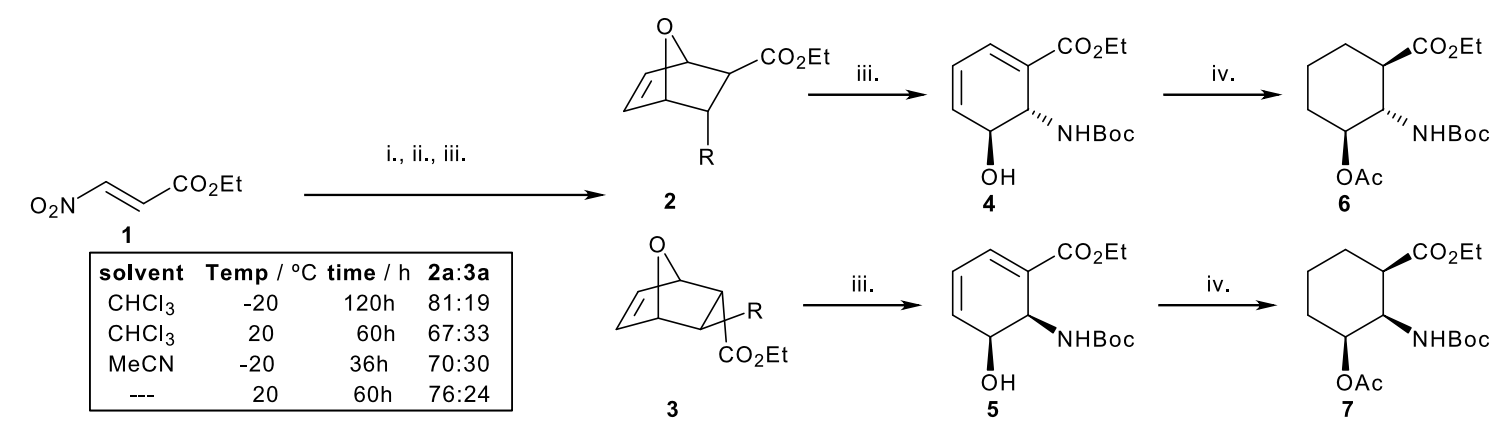

a $\mathrm{R}=\mathrm{NO}_{2}, \mathbf{b} \mathrm{R}=\mathrm{NHBoc}$

Scheme 2: Reagents: i. Furan (see box); ii. $\mathrm{Zn}, \mathrm{HCl}$., EtOH then $\mathrm{Boc}_{2} \mathrm{O}, \mathrm{Et}_{3} \mathrm{~N}, 2 \mathrm{~b} 89 \%, 3 \mathrm{~b} 77 \%$; iii. $\mathrm{KHMDS}, \mathrm{THF},-50^{\circ} \mathrm{C}, 471 \%, 569 \%$; iv. $\mathrm{Ac}_{2} \mathrm{O}, \mathrm{Py}^{2}$ then $\mathrm{H}_{2}$, Pd-C, $675 \%, 775 \%$. 


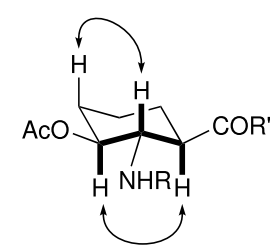

$6 \mathrm{R}=\mathrm{Boc}, \mathrm{R}^{\prime}=\mathrm{OEt}$

$8 \mathrm{R}=\mathrm{Boc}, \mathrm{R}^{\prime}=\mathrm{NHBn}\left(J_{1,2}=J_{2,3}=11.6 \mathrm{~Hz}\right)$

$9 \mathrm{R}=\mathrm{Boc}, \mathrm{R}^{\prime}=\mathrm{NHC}_{6} \mathrm{H}_{11}\left(J_{1,2}=10.2 \mathrm{~Hz}\right)$

Figure 1: Selected NOESY Correlations for 6-9

the literature and our initial experiments followed these precedents. [17-20] Using carbamate $\mathbf{2 b}$, treatment with LDA or LHMDS appeared, by TLC, to give complete conversion extremely rapidly. However, on workup, considerable amounts of the starting ester were recovered. Similar observations have been reported in related systems.[21] Speculating that this was due to either a reversible process or a stabilised, highly coordinated enolate alternative procedures were then explored. Whilst attempts to enhance the fragmentation through the use of various rapid, mildly acidic, inverse quenches or various trapping agents (e.g. TMSCl, TMSOTf) were partially successful, albeit only on very small scale, the use of a less coordinating potassium counterion (KHMDS) allowed the isolation of the dihydroanthranilate esters 4 and 5 in $71 \%$ and $69 \%$ yield respectively together with variable amounts of ethyl 3-hydroxybenzoate. Simple reduction of the corresponding acetates with $\mathrm{H}_{2}$ over Pd-C proved to be highly diastereoselective affording the anti-anti and syn-syn 3-hydroxy-2-aminocyclohexanecarboxylate esters respectively. The stereochemistry was assigned by a combination of NMR techniques using $J$ values supported by nOe correlations, Figure 1. For example, the amide derivatives of the anti-anti isomer 8 and 9 show distinctive large di-axial couplings for $1-H, 2-H$ and $3-H$. Final confirmation of the stereochemistry was achieved by reduction and deprotection of a single enantiomer of carbamate 4 , obtained via resolution of bicyclic ester $\mathbf{2 a}$, to provide 2-amino3-hydroxycyclohexane-1-carboxylate with identical spectroscopic and analytical data to that described in the literature $\left([\alpha]_{\mathrm{D}}{ }^{21}-32\left(\mathrm{c}=1, \mathrm{H}_{2} \mathrm{O}\right)\right.$ lit: $[\alpha]_{\mathrm{D}}{ }^{21}-35\left(\mathrm{c}=1, \mathrm{H}_{2} \mathrm{O}\right) \cdot[22] \mathrm{We}$ attribute the stereochemistry of the reduction of $\mathbf{4}$ to the directing effect of the NBoc carbamate vide infra, whilst the reversal observed with $\mathbf{5}$ can be attributed to the severe steric crowding of the $\beta$-face by the three syn substituents.

\section{3,4-Dihydroxy-2-aminocyclohexane- carboxylic acids}

Having established an efficient entry to the oxanorbornenes and dienyl carbamates we then sort to exploit the alkene units to provide a convenient source of poly-hydroxylated cyclohexane $\beta$-aminoacids. Consequently, treatment of endo derived hydroxy diene with $m$ CPBA in DCM afforded a separable 9:1 mixture of epoxides $\mathbf{1 0}$ and $\mathbf{1 1}$ favouring addition syn to the carbamate, Scheme 3. Highly selective epoxidations of cycloalkenyl amides have been described[23] and, consistent with a hypothesis that the mixture of $\mathbf{1 0}$ and $\mathbf{1 1}$ arise through competing H-bonding directing effects of the carbamate and hydroxyl groups, acetylation of the free hydroxyl group prior to oxidation enhanced the selectivity leading to exclusive formation of 12. In a similar fashion, and in agreement with the idea of two directing groups working in concert, epoxidation of the exo derived diene $\mathbf{5}$ afforded exclusive formation of epoxide $\mathbf{1 3}$. Speculating that disruption of any directing effects through the use of more polar solvents would lead to increased amounts of 12 a range of alternative solvents were screened including THF, DMF, $\mathrm{MeOH}, \mathrm{CF}_{3} \mathrm{CH}_{2} \mathrm{OH}, \mathrm{MeCN}$. Of these, acetonitrile proving the most successful, albeit only providing a 2:1 mixture of isomers. Attempts to further enhance this reversal of selectivity using a variety of alternative procedures were not successful with most methods affording significant quantities of the corresponding protected anthranilic acid.

Having introduced the epoxide function to either face of the diene unit we then sought conditions for regioselective cleavage. In this context, palladium mediated reactions of vinyl epoxides are known to proceed with allylic cleavage.[24] Subsequent addition of hydrogen to the intermediate $\pi$-allyl palladium complex would provide the desired 4-hydroxyACHC derivative. In agreement with this analysis, reaction of the epoxides with hydrogen in the presence of Pd-C afforded

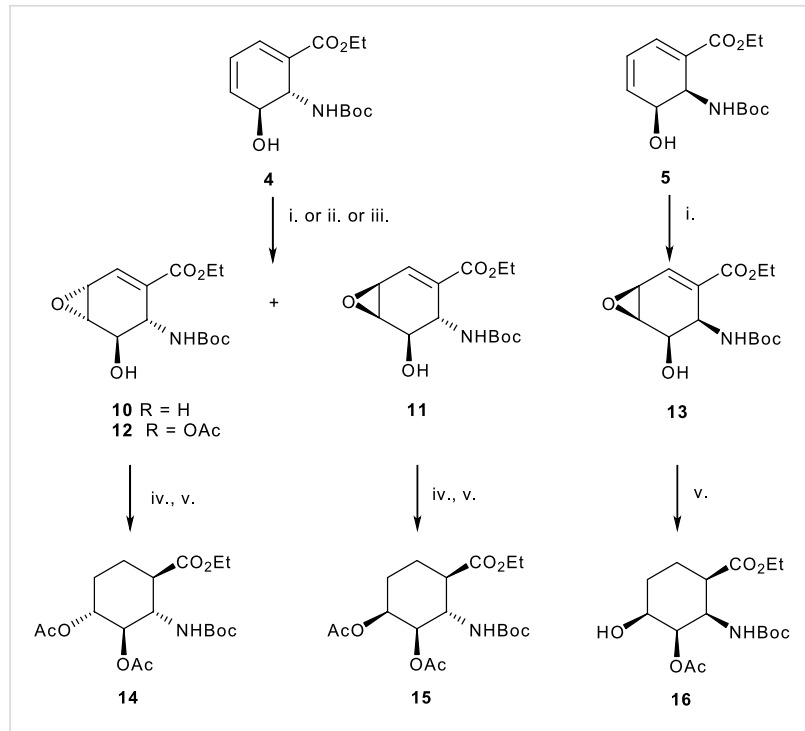

Scheme 3: Reagents: i. mCPBA, $\mathrm{CH}_{2} \mathrm{Cl}_{2} 11$ : 12 (9: 1) $77 \%, 1582 \%$; ii. $\mathrm{Ac}_{2} \mathrm{O}$, Py then mCPBA, $\mathrm{CH}_{2} \mathrm{Cl}_{2}$ (13 only) $65 \%$; iii. mCPBA, $\mathrm{MeCN}$, $\mathrm{NaHCO}_{3} 11$ : 12 (1 : 2) 95\%; iv. Ac $2 \mathrm{O}$, pyridine; v. $\mathrm{H}_{2}, \mathrm{Pd} / \mathrm{C}, 1488 \%$ from $12,1584 \%$ from $11,1697 \%$. 


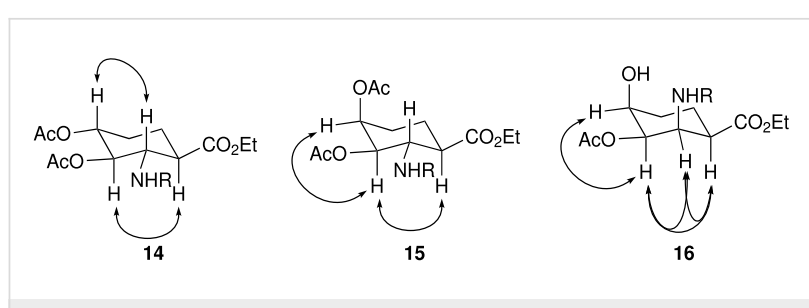

Figure 2: Selected NOESY Correlations for 14-16 ( $\mathrm{R}=\mathrm{Boc})$

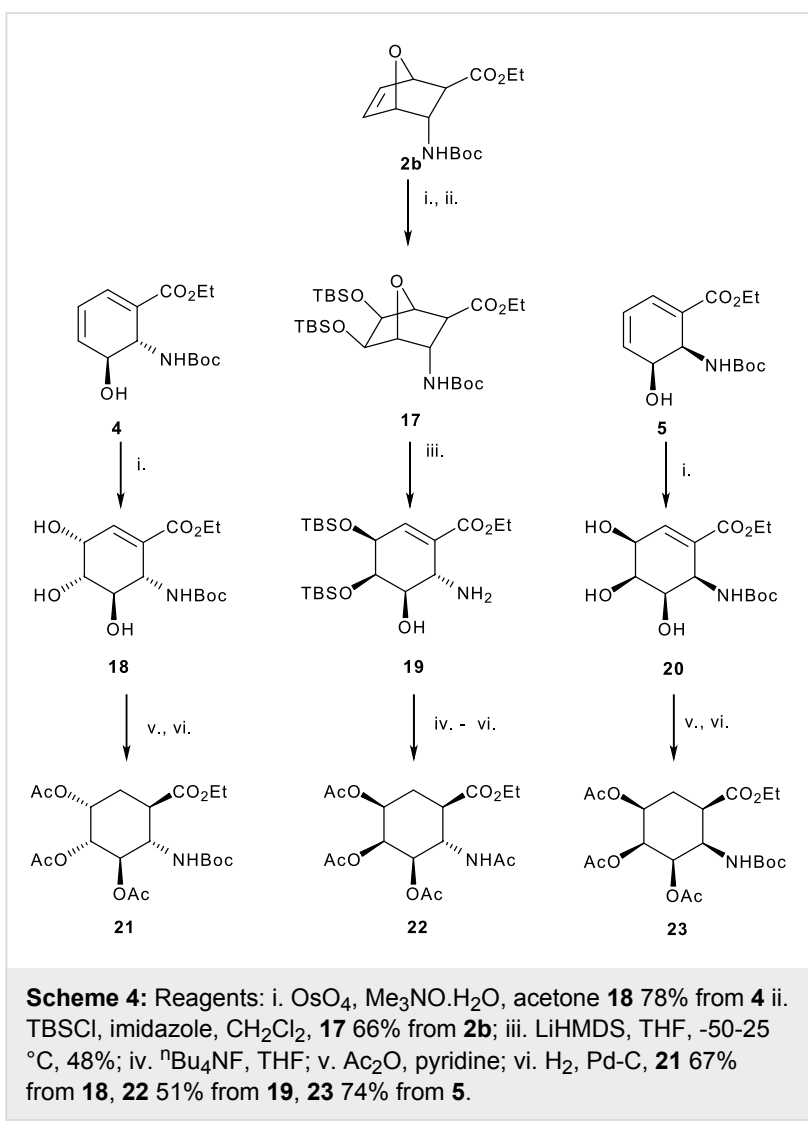

the corresponding 3,4-dihydroxy-2-aminocyclohexancarboxylate derivates 14-16 in excellent yield and diastereoselectivity. In each case the reduction afforded the product with a cis relationship between the 3-hydroxy group and $\mathrm{C}-1$ carboxylate as ascertained by NOESY experiments, Figure 2 . Whilst reactions of allylic electrophiles normally occur with anti attack by the Pd catalyst, the result using 12 suggests possible involvement of the carbamate. In this case the exception occurs with 13 which can be attributed to the severe steric crowding inhibiting such a co-ordination mode.

\section{3,4,5-Trihydroxy-2-aminocyclohexane- carboxylic acids}

The final group of targets we wished to generate was the trihydroxy analogs. Initial attempts addressed the generation of the syn 4,5 set. Consequently, $\mathrm{OsO}_{4}$ mediated dihydroxylation

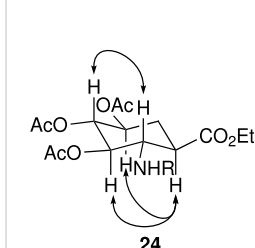

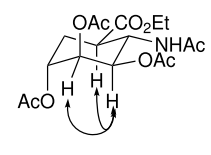

25

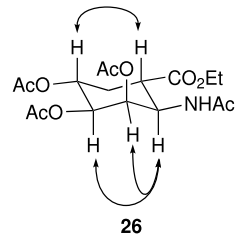

Figure 3: Selected NOESY correlations for $\mathbf{2 4 - 2 6}$ and subsequent peracylation of dienes $\mathbf{4}$ and $\mathbf{5}$ proved to be facio-specific and afforded cyclohexenyl derivatives $\mathbf{1 8}$ and 20 in $75 \%$ yield over the two steps, Scheme 4 . Reduction, as previously, afforded the trihydroxy $\beta$-aminoacid derivatives in excellent yields.

At this stage it is instructive to address the interesting stereochemical outcome of this dihydroxylation reaction. Concurring with our results, Donohoe has reported that cyclic homoallylic carbamates give high levels of syn selectivity in the $\mathrm{OsO}_{4}$ mediated dihydroxylation reactions.[25,26] On the other hand, Kishi has established that the $\mathrm{OsO}_{4}$ mediated oxidation of cyclic allylic alcohols led preferentially to syn-anti triols.[27,28] On the basis of the results from our system where the two processes acted against each other, one can conclude that the homoallylic carbamate ability of stereocontrolling the $\mathrm{OsO}_{4}$ mediated reaction overrides that of the allylic hydroxyl group. Moreover, such directing effects are sufficiently strong that attempts using TMEDA/OsO $\mathrm{O}_{4}$ combinations known to afford syn dihydroxylation of cyclic allylic alcohols were not successful in reversing the selectivity of the reaction with 4 .

In order to introduce the syn diol unit on the opposite face to the carbamate in $\mathbf{4}$ we returned to the oxanorborne cycloadduct in which electrophile additions are known to occur from the exo face. As predicted, smooth selective formation of the desired exo diol 17 was achieved. Following double protection as a bis TBS ether, initial attempts to achieve the desired fragmentation using KHMDS failed. Fortunately, use of LiHMDS was successful albeit accompanied by the unexpected loss of Boc group. Similar strategies using either the free diol or the corresponding acetonide were not successful leading to extensive decomposition. Following TBAF promoted desilylation, peracylation and reduction afforded the trans $\beta$-amino acid derivative $\mathbf{2 2}$ as established by NMR experiments.

Having prepared the 4,5-cis diol, we turned our attention to the synthesis of the corresponding trans diols. These could be prepared by simple hydrolytic cleavage of epoxides 10-13. In line with this plan, treatment of $\mathbf{1 2}$ with aqueous perchloric acid led to a single trans diol, albeit accompanied by the loss of the Boc protecting group. Characterisation of the peracetylated 


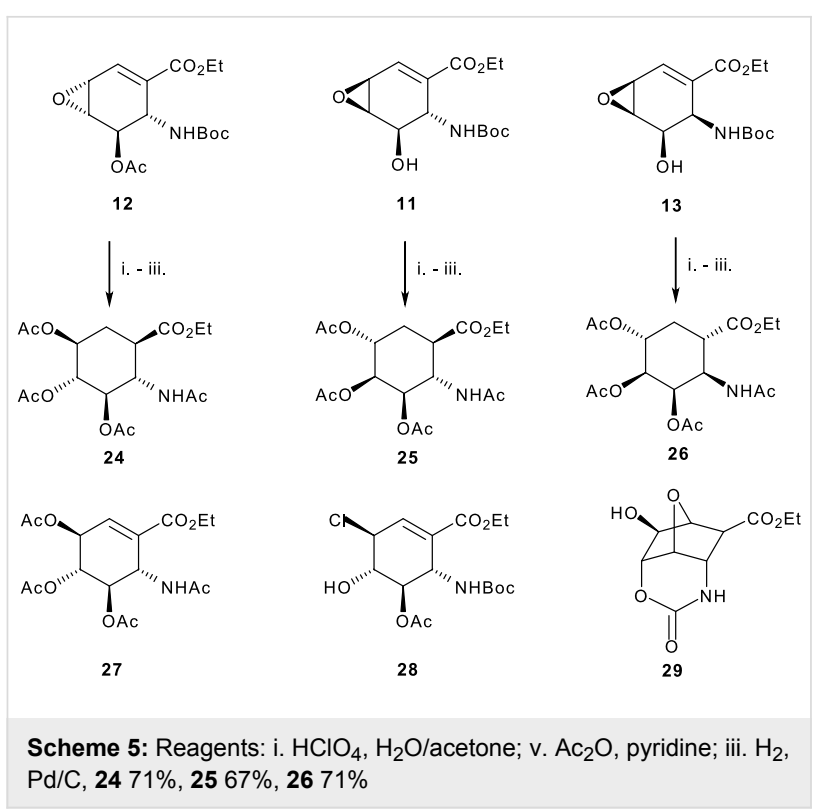

derivative 27 suggested that nucleophilic attack had occurred at the allylic position. Support for this was confirmed by ring opening with $\mathrm{ZnCl}_{2}$ to afford the crystalline chlorohydrin $\mathbf{2 8}$ which was characterised by $x$-ray diffraction. Reduction of the double bond then afforded the expected all anti trihydroxy ACHC isomer 24 as confirmed by 1D and 2D NMR experiments. The observation of $10.0 \mathrm{~Hz} \mathrm{H}_{\mathrm{a}} \mathrm{H}_{\mathrm{b}}$ coupling constants in the ${ }^{1} \mathrm{H}$ NMR spectrum of $\mathbf{2 4}$ for the ring protons (H-1, H-2, $\mathrm{H}-3, \mathrm{H}-4$ and $\mathrm{H}-5$ ) is consistent with anti diaxial relationships. Such assignments are supported by nOe interactions between $\mathrm{H}-1$ and $\mathrm{H}-3, \mathrm{H}-1$ and $\mathrm{H}-5$ and also $\mathrm{H}-2$ and $\mathrm{H}-4$, Figure 3.

Similar treatment of epoxides $\mathbf{1 1}$ and $\mathbf{1 3}$ then afforded the corresponding anti 4,5 diols. Subsequent reduction of the double bond gave the anti-syn-anti-anti and anti-syn-syn-anti isomers $\mathbf{2 5}$ and $\mathbf{2 6}$ as the only detectable products, Scheme 5. In each case it is noteworthy that the reduction proceeded with delivery of hydrogen to the same face as that occupied by the carbamate and opposite to the 3-acetoxy group. As previously, the stereochemical relationships were initially assigned on the basis of 2D NMR experiments, particularly NOESY. Subsequently, the structure of $\mathbf{2 6}$ was confirmed by X-ray crystallographic analysis.

Attempt to generate the remaining epoxide isomer were confounded by an inability to overcome the directing influence of the carbamate and deliver the epoxide to the opposite face of diene 5. Similarly, whilst the alternative regiochemistry in the epoxide ring opening product could be achieved exploiting neighbouring group participation by the NBoc group to afford the cyclic carbamate $\mathbf{2 9}$, all attempts to induce fragmentation of this polycyclic compound have thus far proved unsuccessful.

\section{Conclusion}

In conclusion, we have amplified the utility of the Diels-Alder adducts of ethyl $(E)$-nitroacrylate and furan by devising stereoselective routes to hydroxylated derivatives of 2-aminocyclohexanecarboxylic acid. The principal feature of this approach is the reliance on simple reactions exploiting substrate-controlled selectivity. In this respect, the ability of the carbamate group as a directing group is particularly noteworthy. The use of these hydroxylated cyclohexyl $\beta$-amino acids in the synthesis of short peptides is currently ongoing in our laboratory and will be described in due course.

\section{Supporting Information}

\section{Supporting Information File 1}

Experimental procedures and spectroscopic data are provided for all new compounds including details of the X-ray diffraction studies for compounds $\mathbf{2 b}, \mathbf{2 6}$ and $\mathbf{2 8 .}$ [http://www.beilstein-journals.org/bjoc/content/ supplementary/1860-5397-2-9-S1.doc]

\section{Acknowledgments}

We thank the University of Botswana (IBM) for financial support, Dr A. M. Kenwright for assistance with NMR experiments, Dr M. Jones and the EPSRC National Mass Spectrometry Service, Swansea for mass spectra and Dr Darren Orton for some preliminary experiments.

\section{References}

1. Liu, M.; Sibi, M. P. Tetrahedron 2002, 58, 7991-8035. doi:10.1016/ S0040-4020(02)00991-2

2. Fülöp, F.; Martinek, T. A.; Tóth, G. K. Chem. Soc. Rev. 2006, 35, 323-334. doi:10.1039/b501173f

3. Gellman, S. H. Acc. Chem. Res. 1998, 31, 173-180. doi:10.1021/ ar960298r

4. Appella, D. H.; Christianson, L. A.; Karle, I. L.; Powell, D. R.; Gellman, S. H. J. Am. Chem. Soc. 1996, 118, 13071-13072. doi:10.1021/ ja963290l

5. Cheng, R. P.; Gellman, S. H.; DeGrado, W. F. Chem. Rev. 2001, 101, 3219-3232. doi:10.1021/cr000045i

6. Raguse, T. L.; Lai, J. R.; Le Plae, P. R.; Gellman, S. H. Org. Lett. 2001, 3, 3963-3966. doi:10.1021/ol016868r

7. Appella, D. H.; Christianson, L. A.; Klein, D. A.; Powell, R. D.; Huang, X.; Barchi, J. J. J.; Gellman, H. S. Nature 1997, 387, 381-384. doi:10.1038/387381a0

8. Gademann, K.; Seebach, D. Helv. Chim. Acta 2001, 84, 2925-2937. doi:10.1002/1522-2675(20011017)84:10<2924::AIDHLCA2924>3.0.CO;2-E

9. Guichard, G.; Abele, S.; Seebach, D. Helv. Chim. Acta 1998, 81, 187. doi:10.1002/hlca.19980810202

10. Masesane, I. B.; Steel, P. G. Synlett 2003, 735-737.

11. Masesane, I. B.; Steel, P. G. Tetrahedron Lett. 2004, 45, 5007-5009. doi:10.1016/j.tetlet.2004.05.007 
12. McMurry, J. E.; Musser, J. H. Org. Synth. 1977, 56, 65-68.

13. Danishefsky, S.; Prisbylla, M. P.; Hiner, S. J. Am. Chem. Soc. 1978, 100, 2918. doi:10.1021/ja00477a071

For an exception to this observation see reference [15].

14. Clarke, C.; Fleming, I.; Fortunak, J. M. D.; Gallagher, P. T.; Honan, M. C.; Mann, A.; Nubling, C. O.; Raithby, P. R.; Wolff, J. J. Tetrahedron 1988, 44, 3931. doi:10.1016/S0040-4020(01)86646-1

For an exception to this observation see reference [15].

15. Michael, J. P.; Blom, N. F.; Boeyens, J. C. A. J. Chem. Soc., Perkin Trans. 1 1984, 1739-1743. doi:10.1039/p19840001739

16. Just, G.; Martel, A.; Grozinger, K.; Ramjeesingh, M. Can. J. Chem. 1975, 53, 131-137. doi:10.1139/v75-018

17. Brion, F. Tetrahedron Lett. 1982, 23, 5299-5302. doi:10.1016/S00404039(00)85823-2

18. Rajapaksa, D.; Keay, B. A.; Rodrigo, R. Can. J. Chem. 1984, 62, 826-827. doi:10.1139/v84-137

19. Campbell, M. M.; Sainsbury, M.; Searle, P. A. Synthesis 1993, 179-193. doi:10.1055/s-1993-25824

20. Evans, D. A.; Barnes, D. M. Tetrahedron Lett. 1997, 38, 57-58. doi:10.1016/S0040-4039(96)02259-9

21. Couche, E.; Deschatrettes, R.; Poumellec, K.; Bortolussi, M.; Mandville, G.; Bloch, R. Synlett 1999, 87-89. See also reference [20].

22. McCormick, D. R. J.; Reichenthal, J.; Hirsch, U.; Sjolander, N. O. J. Am. Chem. Soc. 1961, 83, 4104-4105. doi:10.1021/ja01480a043

23. Barrett, S.; O'Brien, P.; Steffens, H. C.; Towers, T. D.; Voith, M. Tetrahedron 2000, 56, 9633-9640. doi:10.1016/S0040-4020(00)00911$\mathrm{X}$

24. Trost, B. M.; Angle, S. R. J. Am. Chem. Soc. 1985, 107, 6123-6124. doi:10.1021/ja00307a059

25. Donohoe, T. J.; Mitchell, L.; Waring, M. J.; Helliwell, M.; Bell, A.; Newcombe, N. J. Tetrahedron Lett. 2001, 42, 8951-8954. doi:10.1016/ S0040-4039(01)01999-2

26. Donohoe, T. J.; Blades, K.; Moore, P. R.; Waring, M. J.; Winter, J. J. G.; Helliwell, M.; Newcombe, N. J.; Stemp, G. J. Org. Chem. 2002, 67, 7946-7956. doi:10.1021/jo026161y

27. Cha, J. K.; Christ, W. J.; Kishi, Y. Tetrahedron Lett. 1983, 24 3943-3946. doi:10.1016/S0040-4039(00)88231-3

28. Cha, J. K.; Christ, W. J.; Kishi, Y. Tetrahedron 1984, 40, 2247-2255. doi:10.1016/0040-4020(84)80008-3

\section{License and Terms}

This is an Open Access article under the terms of the Creative Commons Attribution License (http://creativecommons.org/licenses/by/2.0), which permits unrestricted use, distribution, and reproduction in any medium, provided the original work is properly cited.

The license is subject to the Beilstein Journal of Organic Chemistry terms and conditions: (http://www.beilstein-journals.org/bjoc)

The definitive version of this article is the electronic one which can be found at: doi:10.1186/1860-5397-2-9 